\title{
Baicalein Inhibits Proliferation Activity of Human Colorectal Cancer Cells HCT116 Through Downregulation of Ezrin
}

\author{
Zhi Chen $^{\mathrm{a}}$ Ruizhi Hou ${ }^{\mathrm{b}}$ Shuohui Gao ${ }^{\mathrm{b}}$ Defeng Song ${ }^{\mathrm{b}}$ Ye Feng ${ }^{\mathrm{b}}$ \\ aDepartment of Nephrology, First Hospital of Jilin University, Changchun, bepartment of \\ Gastrointestinal Colorectal and Anal Surgery, China-Japan Union Hospital of Jilin University, \\ Changchun, China
}

\author{
Key Words \\ Colorectal cancer • Baicalein • Ezrin • P53 pathway
}

\begin{abstract}
Background/Aims: The present study was aimed at examining Ezrin expression in human colorectal cancer (CRC) tissues and elucidating the influence of baicalein on the proliferation of HCT116 cells. Methods: The expression of Ezrin was determined by qRT-PCR and immunohistochemistry. HCT116 cells were divided into four groups - baicalein groups with various concentrations, pcDNA3.1-Ezrin group, si-Ezrin group and dual inhibitory group (baicalein + si-Ezrin). CCK-8 assay and flow cytometry (FCM) were employed to assess cell proliferation and to detect the distribution of cell cycle respectively. The expression levels of Ezrin protein and cell cycle-associated proteins were detected by using western blot. The proliferation ability of CRC cells was also evaluated in vivo. Results: Ezrin expression in CRC tissues was observably higher than that in adjacent colorectal tissues. With drug concentration and action time of baicalein increasing, the cell propagation capacity of HCT116 cells was decreased and the cell cycle progression was arrested. Ezrin expression was inhibited by the administration of baicalein in a dose-dependent way. The levels of CyclinD1 and CDK4 were also significantly decreased, but the expression of P53 pathway proteins P53 and P21 was markedly upregulated. Conclusion: Baicalein repressed proliferation of human colorectal cancer cells HCT116 and blocked cell cycle through downregulating Ezrin and upregulating P53 pathway-related proteins.

\section{Introduction}

Colorectal cancer (CRC) is one of the most malignant cancers diagnosed in the gastrointestinal tract (GIT), which requires different staging criteria, adjuvant treatment and operative methods [1]. Environment and genetic factors have been long-standing issues in the germination and progression of colon cancer [2]. With the application of advanced technologies like deep deoxyribonucleic acid (DNA) sequencing [3], recent researches have 


\section{Cellular Physiology Cell Physiol Biochem 2018;49:2035-2046

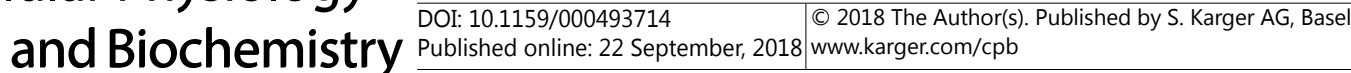 \\ Chen et al.: Baicalein Affects HCT116 Cells by Regulating Ezrin}

revealed that CRC is the most complex cancer at a genetic level [4]. Colon cancer patients treated with surgery and adjuvant radio- or chemo- therapies showed no difference in health related quality of life (HRQoL) and disease-specific survival (DSS) [5]. Therefore, it is imperative to develop an effective therapeutic approach for CRC.

Baicalein (5, 6, 7-trihydroxyflavone) is one of the naturally active ingredients derived from a Chinese herb. It has been reported that baicalein is closely related to osteoclast differentiation [6]. What's more, several studies have found that baicalein exerts antiinflammatory and anti-cancer effects in a broad spectrum of cancers [7].. For example, baicalein can induce apoptosis and inhibit metastasis of prostate cancer cells through inactivation of the caveolin-1/AKT/mTOR pathway [8]. Besides, it has been demonstrated that baicalein has efficient anticancer effects on hepatocellular carcinoma (HCC) to suppress cell growth and cell survival via the alteration of either microRNA [9] or mRNA expression profiles, the adjustment in the expression of CD24 included [10]. Beyond that, the activation of the AMPK/ULK1 pathway induced by baicalein is associated with a variety of human cancers [11]. Wang CZ et al. investigated the chemopreventive effects of baicalein in colon cancer and verified its significant antiproliferative effects on colon cancer cells in in vitro and in vivo assays [12]. However, the underlying molecular mechanisms of baicalein in CRC remain to be further elucidated.

Ezrin, also known as cytovillin or villin-2, is a prototypical member of a protein family, ERM (Ezrin/ Radixin/ Moesin). The ERM protein family contains a series of linking proteins which function in connecting the actin cytoskeleton and the plasma membrane [13]. Increasing researches focus on the role of Ezrin in cancer invasion and metastasis since its initial identification. Overexpression of Ezrin is an independent prognostic factor with poor overall survival (OS) and disease-free survival (DFS) in pancreatic ductal adenocarcinomas [14], breast cancer [15] and oral squamous cell carcinoma (OSCC) [16], indicating the tumorpromotor function of Ezrin. Additionally, the expression and phosphorylation of Ezrin play a novel role in the apoptosis and proliferation of multiple human cancer cell lines [17-19]. It has been revealed that Ezrin-related signaling pathways have modification effects on several downstream effector proteins, contributing to the development of human cancers.

In this research, we performed RT-qPCR analysis and immunohistochemical method to detect the Ezrin level in CRC tissues and adjacent colorectal tissues. Ezrin levels were significantly elevated in poorly-differentiated CRC tissues compared with well-differentiated, moderately-differentiated CRC tissues and adjacent normal colorectal tissues. We hypothesized that baicalein inhibited proliferation activity of CRC cells via downregulation of Ezrin. In colorectal carcinogenesis, increased baicalein and Ezrin collaboratively contributed to the reduction of HCT116 cell growth and inhibition of CRC progression.

\section{Materials and Methods}

\section{Clinical samples}

CRC tissue samples used were collected from 80 colorectal neoplasm patients who underwent neither radiotherapy nor chemotherapy in First Hospital of Jilin University, including 50 well-differentiated or moderately-differentiated CRC tissues and 30 poorly differentiated ones. This research had been authorized by the medical ethics committee of First Hospital of Jilin University and obtained informed written consents from all participants involved. 25 para-carcinoma tissues were harvested as normal controls. These tissue specimens were kept in the $-80^{\circ} \mathrm{C}$ cryogenic refrigerator followed by extraction and collection. Human colorectal neoplasm cell line HCT116 was purchased from BeNa culture Collection (BNCC, Shanghai, China) and cultured in 90\% RPMI-1640 medium $+10 \%$ FBS (BNCC) and 1\% Penicillin/ Streptomycin (Invitrogen, Carlsbad, CA).

\section{Primary cell culture, cell passage and cell transfection}

HCT116 cells were maintained at $37^{\circ} \mathrm{C}, 5 \% \mathrm{CO}_{2}$ in the humidified environment. Baicalein was added at the concentration of $0 \mu \mathrm{mol} / \mathrm{L}, 20 \mu \mathrm{mol} / \mathrm{L}$ or $40 \mu \mathrm{mol} / \mathrm{L}$ for $24 \mathrm{~h}$ or $48 \mathrm{~h}$. Specific groups and interventions are as follows: blank control (NC) group ( $1 \mu \mathrm{l} / \mathrm{ml} \mathrm{PBS})$, solvent control (DMSO) group(DMSO=0.05\%), $20 \mu \mathrm{mol} / \mathrm{L}$ baicalein group (dissolved in DMSO, DMSO=0.05\%), 40 $\mu \mathrm{mol} / \mathrm{L}$ baicalein group (dissolved in DMSO, DMSO=0.05\%); Negative control (NC) group, pcDNA3.1-Ezrin group (50nmol/L), si-Ezrin group $(50 \mathrm{nmol} / \mathrm{L})$, dual inhibitory group $(50 \mathrm{nmol} / \mathrm{L}$ si-Ezrin and $20 \mu \mathrm{mol} / \mathrm{L}$ baicalein). Baicalein was purchased 


\section{Cellular Physiology Cell Physiol Biochem 2018;49:2035-2046

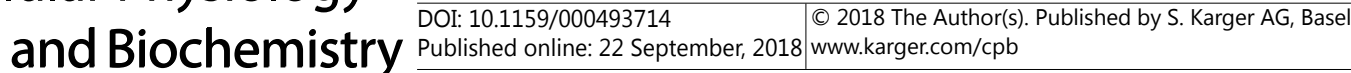 \\ Chen et al.: Baicalein Affects HCT116 Cells by Regulating Ezrin}

from Sangon Biotech (Shanghai, China) and the pcDNA3.1 plasmid vectors and siRNA sequences were provided by GenePharma Co., Ltd (Shanghai, China). The HCT116 cell line was transfected by using Lipo2000 (Invitrogen).

\section{Envision two-step immunohistochemical staining method}

The deparaffinized and rehydrated sections were rinsed with PBS. The microwave antigen repair technique was used for $2 \mathrm{~min}$ and then the sections were naturally cooled down at $-37^{\circ} \mathrm{C}$. The histologic sections were incubated in 3\% hydrogen peroxide $\left(\mathrm{H}_{2} \mathrm{O}_{2}\right)$ for 15 min to block endogenous peroxidase activities. Afterwards, the sections were incubated with primary antibodies at $4^{\circ} \mathrm{C}$ overnight (rabbit antiEzrin, 1:200; mouse anti-Ki67, 1:200; Abcam, Cambridge, MA). On the following day, the sections were exposed for $1 \mathrm{~h}$ at room temperature and then washed in PBS for three times ( 4 min each time). Then they were mixed with biotinylated secondary antibodies for $30 \mathrm{~min}$ at $37^{\circ} \mathrm{C}$ (Goat Anti-Rabbit IgG H\&L, Goat Anti-Mouse IgG H\&L, 1:1000; Abcam). Having been diluted with diaminobenzidine (DAB), the sections were blended with hematoxylin dye for $10 \mathrm{~min}$. Finally, anhydrous alcohol was added for fixation and neutral gum was applied as mounting medium. The staining feature was detected by means of a fluorescence microscope system.

\section{CCK-8 assay}

HCT116 cells were seeded in a 96-well culture plate $(100 \mu \mathrm{l} /$ well $)$ at a density of $1 \times 10^{5}$ cells/ well and were subjected to transfection. The transfected cells were incubated with CCK- 8 reagent $(10 \mu \mathrm{l} /$ well, DOJINDO, Japan) for $4 \mathrm{~h}$ at $37^{\circ} \mathrm{C}, 5 \% \mathrm{CO}_{2}$ in a humidified incubator. Proliferation capability was determined within one week after transfection. The absorbance of each well was measured with a microplate reader at a wavelength of $450 \mathrm{~nm}$. Cell growth inhibitory rate (\%) = (1- average optical density of experimental group/ control group) $\times 100 \%$.

\section{Cell-cycle analysis using flow cytometry}

HCT116 cells in each well were digested with trypsin, washed in PBS twice and centrifuged at the rate of $1000 \mathrm{rpm}$ for $5 \mathrm{~min}$. After the supernatant was abandoned, the cells were then fixed with $75 \%$ cold alcohol $(2 \mathrm{ml})$ and immobilized for $12 \mathrm{~h}$ at $4^{\circ} \mathrm{C}$. Thereafter, the cells were centrifuged again and the supernatant was discarded. $10 \mu \mathrm{L}$ of $1 \mathrm{mg} / \mathrm{mL}$ PI solution (the final concentration being $10 \mu \mathrm{g} / \mathrm{mL}$ ) and $5 \mu \mathrm{L}$ of $10 \mathrm{mg} / \mathrm{mL}$ Rnase A (the final concentration being $0.2 \mathrm{mg} / \mathrm{mL}$ ) were then added and incubated in the dark for $15 \mathrm{~min}$ at room temperature. A flow cytometer was used to analyze the cell cycle.

\section{Western blot}

The total protein was extracted by using RIPA lysis buffer $(100 \mu l$, Beyotime, Shanghai, China). Lysates were centrifuged on ice for $20 \mathrm{~min}$, followed by supernatants collection. BCA assay was utilized to determine the protein concentration. Proteins $(20 \mu \mathrm{g})$ were loaded and electrophoresed by using SDS-PAGE at $90 \mathrm{~V}$ for $1.5 \mathrm{~h}$, which were subsequently transferred to PVDF membranes. The membranes were blocked for $1 \mathrm{~h}$ in 5\% skim milk and then washed with PBST. Afterwards, the membranes were cultured with primary antibodies at $4^{\circ} \mathrm{C}$ overnight, followed by addition of secondary antibodies for another one-hour incubation. The membranes were washed three times for $5 \mathrm{~min}$ with TBST buffer. Finally, proteins were visualized through the ECL plus system. The primary antibodies included rabbit anti-Ezrin, rabbit anti-CyclinD1, rabbit anti-CDK4, mouse anti-P53 and rabbit anti-P21 (diluted 1: 200, Abcam); the secondary antibodies incorporated Goat Anti-Rabbit IgG H\&L and Goat Anti-Mouse IgG H\&L antibodies. $\beta$-actin was used as an internal reference.

\section{qRT-PCR}

Total RNA was extracted from the CRC cells and tissues by using Trizol reagent (Invitrogen). The level of RNA transcripts was detected in RT-qPCR assay. Briefly, cDNA was synthesized by Super Script ${ }^{\mathrm{TM}}$ III Platium ${ }^{\circledR}$ One-step reverse transcriptase (Invitrogen) from $2 \mu \mathrm{g}$ of total RNA. Real-time fluorescent quantitative PCR was performed on the CFX96 Touch $^{\text {TM }}$ Real-Time PCR Detection System (Bio-rad, CA, USA). $\beta$-actin was utilized for normalization. The forward and reverse primer sequences were listed in Table 1.

The xenograft models of nude mice

Nude mice were purchased from Laboratory Animal Center of Guangzhou Medical University (Guangzhou, China), and maintained under controlled temperature $\left(28^{\circ} \mathrm{C}\right)$ and specific-pathogen-free (SPF) conditions at First Hospital of Jilin University. All procedures were performed aseptically in accordance with the institutional guidelines of First Hospital of Jilin University and approved by the Experimental Animal Ethics Committee of First Hospital of Jilin University. Xenografts were established by subcutaneous injection 


\section{Cellular Physiology Cell Physiol Biochem 2018;49:2035-2046

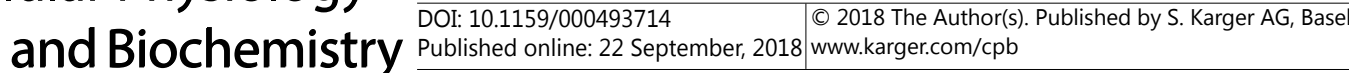 \\ Chen et al.: Baicalein Affects HCT116 Cells by Regulating Ezrin}

of $1 \times 10^{6}$ wild-type HCT116 cells in the right flank region of each nude mouse. A total of sixteen 4-6-week-old female nude mice of the Balb/c strain were divided into four groups ( $\mathrm{n}=4$ each group). Treatment with sh-Ezrin (GenePharma) or/and $50 \mathrm{mg} / \mathrm{kg}$ baicalein was initiated at the $4^{\text {th }}$ day post-implantation, and HCT116 xenografts had reached tumor volumes of about $250 \mathrm{~mm}^{3}$. The treatment protocol consisted of 3 weekly cycles, and each cycle included two consecutive days of sh-Ezrin or/and $50 \mathrm{mg} / \mathrm{kg}$ baicalein treatment through intraperitoneal injections. To assess drug effects on xenografts growth, the tumor growth in the nude mice was observed every five days and the size of tumor was recorded. The tumor volumes (V) were determined by measuring the length (a) and width (b) with calipers every week and reckoned using the formula: $V\left(\mathrm{~mm}^{3}\right)=1 / 2^{*} \mathrm{ab}^{2}$. The mice were not sacrificed until the end of the treatment period, and tumors were collected for weighing and immunochemical studies.

\section{Statistical analysis}

All experiments were performed in triplicate. Statistical analysis was carried out by means of SPSS software (version 19.0) and all data were presented as mean \pm standard deviation. Results of immunohistochemistry were analyzed by Chi-square $\chi 2$ test of fourfold table, while one-Way ANOVA and Tukey post-hoc multiple comparison tests were applied to other assays. In this study, $P<0.05$ was considered to be statistically significant.

\section{Results}

Expression of Ezrin in tissues with various differentiation grades

QRT-PCR detected the distinction in the expression levels of Ezrin between human colorectal neoplasm tissues and adjacent colorectal tissues. It was revealed that the expression of Ezrin in human colorectal cancer tissues was significantly elevated compared with that in adjacent colorectal tissues $(P<0.05$, Fig. $1 \mathrm{~A})$. As shown in the CCK-8 assay, with the down-regulation of Ezrin expression, the optical absorbance of HCT116 cells was decreased while the growth inhibition rate was gradually enhanced $(P<0.05$, Fig. 1B). Furthermore, the immunohistochemistry assay also indicated that Ezrin protein was highly expressed in human colorectal neoplasm tissues in contrast to normal colorectal tissues (Fig. 1C). Obvious positive granules were detected in poorly differentiated colorectal neoplasm tissues, which outnumbered those in well-differentiated and moderately-differentiated CRC tissues (Fig. 1D).

Pathological significance of Ezrin expression in human colorectal neoplasm

In addition, we also investigated the relationship among Ezrin expression level, gender and age of patients, diameter, differentiation grade and the Dukes stage of the tumor, or lymph node metastasis. As exhibited in Table 2, the expression of Ezrin was higher in poorlydifferentiated cases than in well- and moderately-differentiated cases $(P<0.05)$. Meanwhile, the positive rate of Ezrin on Dukes C and D stages was higher than that on Dukes A and B stages $(P<0.05)$. However, there was no significant association of the expression of Ezrin with gender, age, size of the tumor and lymph node metastasis $(P>0.05)$.

\section{Effects of baicalein on proliferation of HCT116 cells}

HCT116 cells were treated respectively for $24 \mathrm{~h}$ or $48 \mathrm{~h}$ with Blank control (NC), solvent control (DMSO), $20 \mu \mathrm{mol} / \mathrm{L}$ baicalein and $40 \mu \mathrm{mol} / \mathrm{L}$ baicalein. With the increasing concentrations and time of drug action, cell growth was gradually attenuated. The results of CCK-8 assay showed that baicalein exerted inhibitory influence on HCT116 cell proliferation in a both dose- and time-dependent manner (all $P<0.05$, Fig. $2 \mathrm{~A}$ ). No significant difference was observed between DMSO group and NC group in terms of cell density absorbance $(P>0.05)$. As HCT116 cells treated for $48 \mathrm{~h}$ showed more obvious differences than HCT116 cells treated for $24 \mathrm{~h}$, the following experiments were all based on 48-hour drug treatment. The arrest of the HCT116 cell cycle in the G1 phase was increasingly induced with $20 \mu \mathrm{mol} / \mathrm{L}$ 


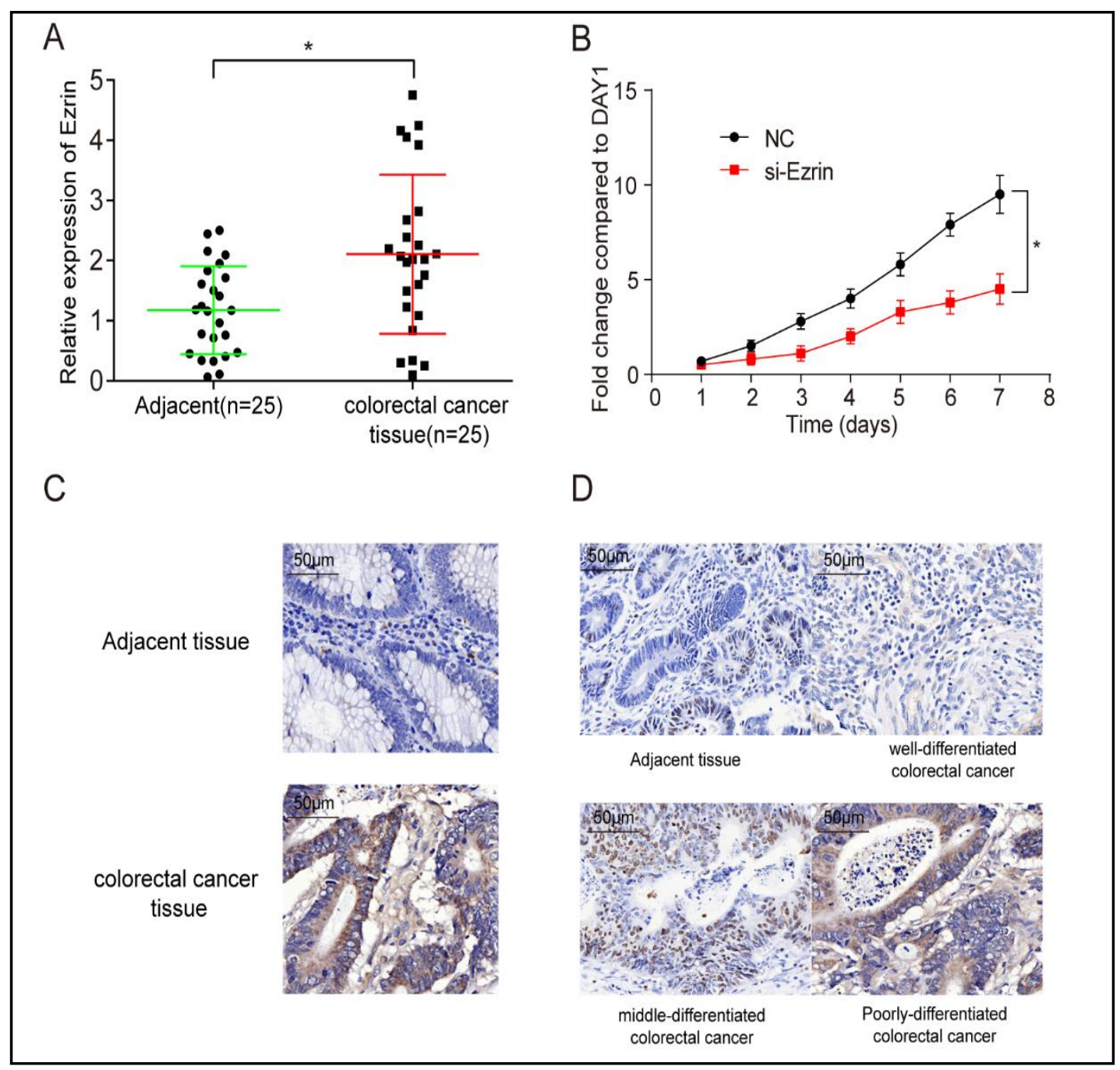

Fig. 1. Expression of Ezrin in tissues with various differentiation grades. (A) Expression of Ezrin in CRC tissues and normal para-carcinoma tissues determined by qRT-PCR. (B) Growth curve of HCT116 cells in si-Ezrin group in comparison to that of HCT116 cells in negative control (NC, transfection with nonspecific siRNA) group. (C) Expression of Ezrin in colorectal neoplasm tissues and normal para-carcinoma tissues determined by immunohistochemical method. (D) Expression of Ezrin in colorectal cancer tissues with various differentiation grades, including well differentiated colorectal cancer tissues, moderately differentiated colorectal cancer tissues and poorly differentiated colorectal cancer tissues. $\left({ }^{*} \mathrm{P}<0.05\right.$ vs Control).

and $40 \mu \mathrm{mol} / \mathrm{L}$ treatment of baicalein, leading to the suppressive effects on cell proliferation (all $P<0.05$, Fig. 2B-2C). All the above results suggested that baicalein could effectively inhibit the proliferation activity of HCT116 cells.

Mechanisms of baicalein-induced cell cycle arrest in HCT116 cells

The mRNA (Fig. 3A) and protein (Fig. 3B-3C) expression levels of Ezrin, as well as cellcycle regulatory proteins CyclinD1 and CDK4 and P53 pathway-related proteins P53 and P21, were detected by qRT-PCR and Western blot. The expression levels of Ezrin were gradiently decreased with increasing concentrations of baicalein treatment $(P<0.05)$. The expression levels of CyclinD1 and CDK4 were downregulated $(P<0.05)$, which indicated that baicalein effectively down-regulated the Ezrin mRNA and protein levels and suppressed expression of cell cycle-related proteins, thereby inducing cell cycle arrest in HCT116 cells. The expression 
levels of P53 and P21 were increased by baicalein treatment in a concentration-dependent manner $(P<0.05)$, which suggested that baicalein suppressed the expression of cell cyclerelated proteins via P53-dependent pathway.

\section{Effects of si-Ezrin on proliferation activity of HCT116 cells}

The results of CCK-8 assay showed that after si-Ezrin transfection, cell proliferation was also effectively suppressed while cell proliferation was markedly promoted after pcDNA3.1Ezrin transfection $(P<0.05)$. Besides, there was statistically significant difference in absorbance between $20 \mu \mathrm{mol} / \mathrm{L}$ baicalein group $(P<0.05)$ or dual inhibitory group $(P<0.01)$ and $\mathrm{NC}$ group (Fig. 4A). Flow cytometry analysis (Fig. 4B-4C) indicated that the percentage of G1 phase in si-Ezrin group, $20 \mu \mathrm{mol} / \mathrm{L}$ baicalein group and dual inhibitory group was gradually increased, whereas the percentage of $S$ phase was remarkably decreased compared with NC group. The distribution of cell cycle in pcDNA3.1Ezrin group displayed the adverse trend. Furthermore, the percentage of $\mathrm{S}$ phase in si-Ezrin group was increased in comparison with baicalein group and dual inhibitory group $(P<0.01)$. These results suggested that both si-Ezrin and baicalein led to cell-cycle arrest on the G1 stage, and their combination had a synergistic effect. Taken together, these results revealed

Table 2. Pathological significance of Ezrin expression in human colorectal cancer. * represented $\mathrm{P}<0.05$

\begin{tabular}{|c|c|c|c|c|c|c|}
\hline Clinicopathological Parameter & $\mathrm{n}$ & & & $\begin{array}{l}\text { n expression } \\
\text { Positive Rate (\%) }\end{array}$ & $\chi^{2}$ & $P$ \\
\hline \multicolumn{7}{|l|}{ Gender } \\
\hline Male & 42 & 11 & 31 & 73.8 & \multirow{2}{*}{0.691} & \multirow{2}{*}{0.406} \\
\hline Female & 38 & 7 & 31 & 81.6 & & \\
\hline \multicolumn{7}{|l|}{ Age } \\
\hline$<60$ & 41 & 9 & 32 & 78.0 & \multirow{2}{*}{0.015} & \multirow{2}{*}{0.904} \\
\hline$\geq 60$ & 39 & 9 & 30 & 76.9 & & \\
\hline \multicolumn{7}{|l|}{ Diameter (cm) } \\
\hline$<3$ & 16 & 6 & 10 & 62.5 & \multirow{2}{*}{2.581} & \multirow{2}{*}{0.108} \\
\hline$\geq 3$ & 64 & 12 & 52 & 81.3 & & \\
\hline \multicolumn{7}{|l|}{ Differentiated degree } \\
\hline Well/ Moderately differentiated & 50 & 15 & 35 & 70.0 & \multirow{2}{*}{4.301} & \multirow{2}{*}{$0.038^{*}$} \\
\hline Poorly differentiated & 30 & 3 & 27 & 90.0 & & \\
\hline \multicolumn{7}{|l|}{ Dukes stages } \\
\hline$A$ and $B$ stages & 44 & 14 & 30 & 68.2 & \multirow{2}{*}{4.869} & \multirow{2}{*}{$0.027^{*}$} \\
\hline $\mathrm{C}$ and $\mathrm{D}$ stages & 36 & 4 & 32 & 88.9 & & \\
\hline \multicolumn{7}{|l|}{ Lymphatic metastasis } \\
\hline Yes & 34 & 5 & 29 & 85.3 & \multirow{2}{*}{2.060} & \multirow{2}{*}{0.151} \\
\hline No & 46 & 13 & 33 & 71.7 & & \\
\hline
\end{tabular}

B

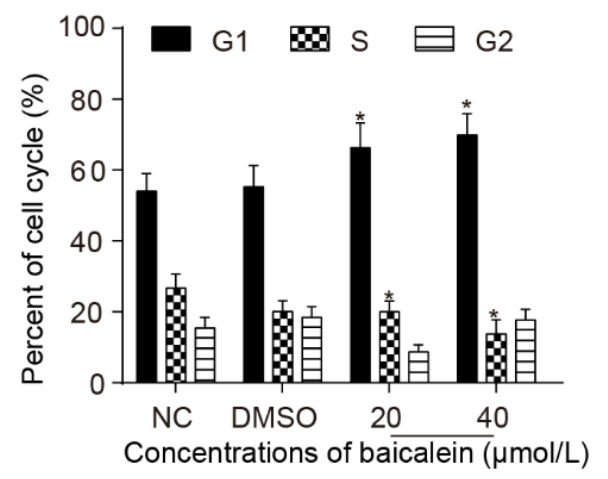

C
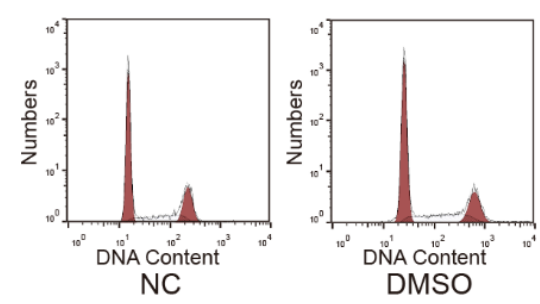

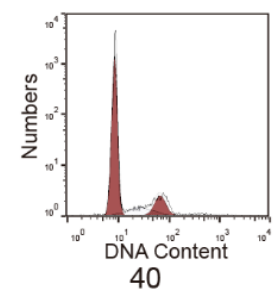

40

Concentrations of baicalein $(\mu \mathrm{mol} / \mathrm{L})$

Fig. 2. Effects of baicalein on proliferation activity of HCT116 cells. (A) The cell proliferative ability of each group was determined by CCK-8 assay: a. blank control (NC) group $(1 \mu \mathrm{l} / \mathrm{ml} \mathrm{PBS})$; b. Solvent control (DMSO) group (DMSO $=0.05 \%$ ); c. $20 \mu \mathrm{mol} / \mathrm{L}$ baicalein group (dissolved in DMSO, DMSO $=0.05 \%$ ); d. $40 \mu \mathrm{mol} / \mathrm{L}$ baicalein group (dissolved in DMSO, DMSO $=0.05 \%$ ). (B-C) The percentage of G1 phase in HCT116 cells was increased gradually by baicalein in a dose-dependent manner, while the percentage of $\mathrm{S}$ phase was gradually decreased. $\left({ }^{*} \mathrm{P}<0.05\right.$ vs Solvent Control (DMSO); $\# \mathrm{P}<0.05$ vs $24 \mathrm{~h}$ ). 
Fig. 3. Mechanisms of baicalein-induced cell cycle arrest in HCT116 cells. (A) The mRNA expression levels of Ezrin, as well as cellcycle regulatory proteins CyclinD1 and CDK4 and P53 pathway-related proteins P53 and P21, were detected by qRTPCR. (B-C) The protein expression levels of the factors mentioned above were validated by Western blot. $\left({ }^{*} \mathrm{P}<0.05\right.$ vs Solvent Control (DMSO); $\quad{ }^{*} \mathrm{P}<0.01 \quad$ vs Solvent Control (DMSO); $\# \mathrm{P}<0.05$ vs $20 \mu \mathrm{mol} / \mathrm{L}$

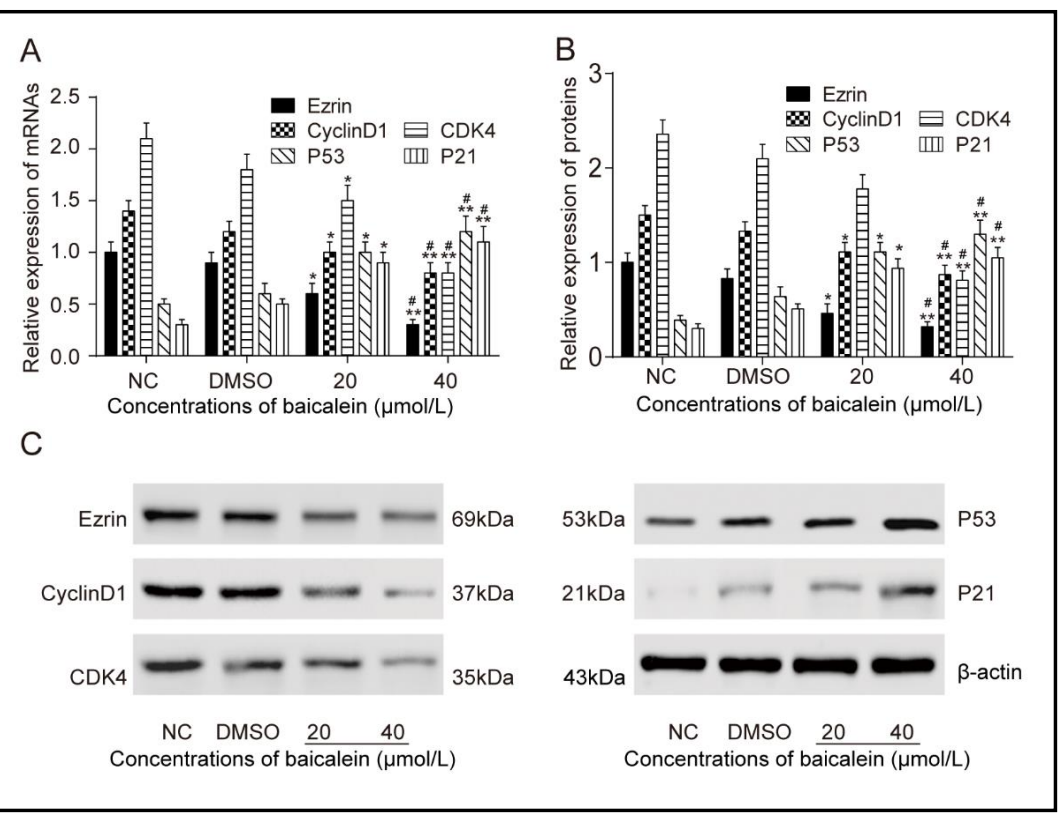
baicalein group).

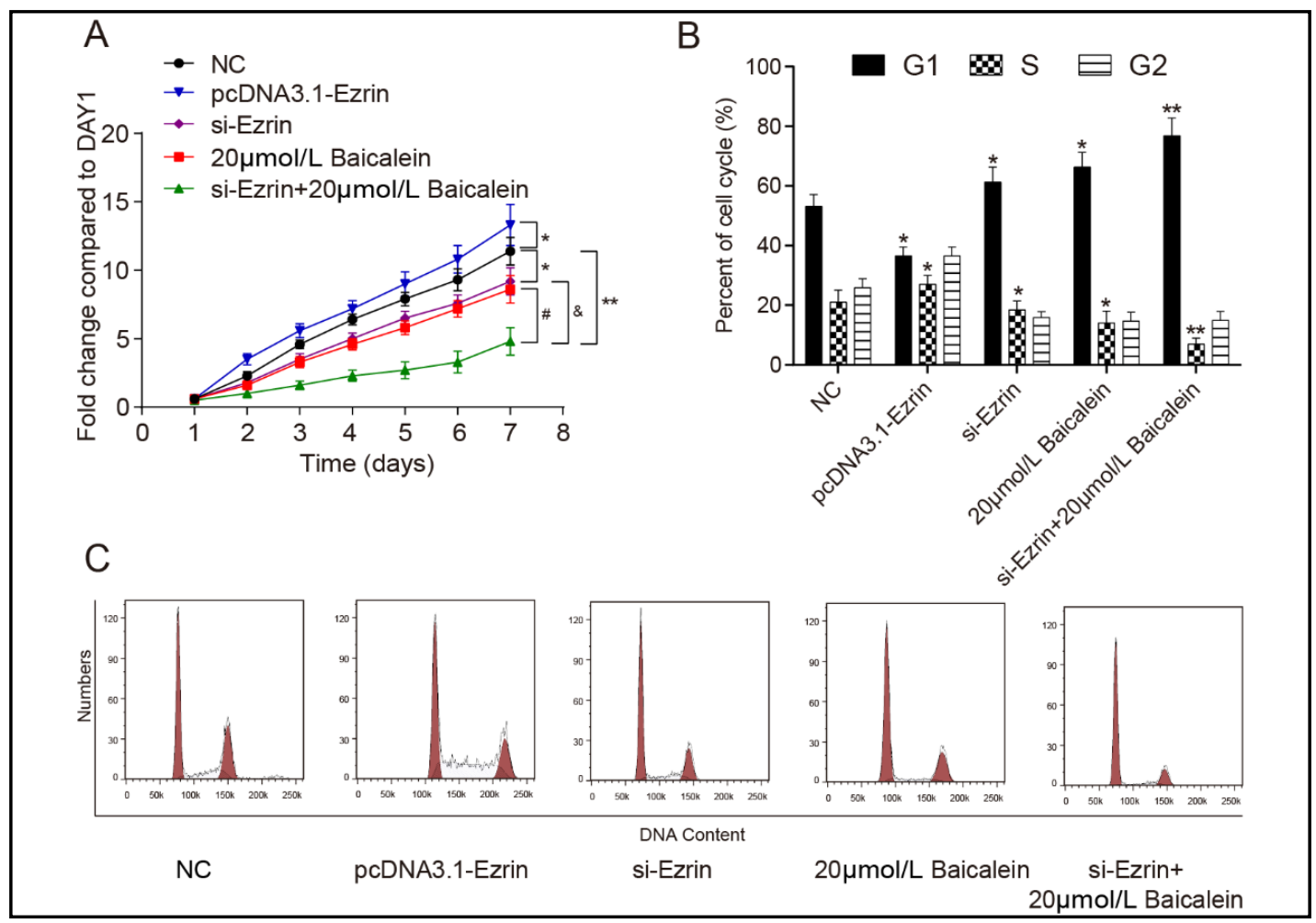

Fig. 4. Effects of si-Ezrin on proliferation activity of HCT116 cells. (A) The si-Ezrin group, 20 $\mu$ mol/L baicalein group and dual inhibitory group could all suppress the HCT116 cell proliferation compared to NC (transfection with empty vector and non-specific siRNA) group, while pcDNA3.1-Ezrin group accelerated HCT116 cell proliferation. Meanwhile, the inhibition ratio of si-Ezrin group was lower than the baicalein group and the dual inhibitory group had the highest suppression rate. (B-C) The percentage of G1 phase in si-Ezrin group, baicalein group and dual inhibitory group was increased gradually and the percentage of S phase was gradually decreased. The percentage of G1 phase in si-Ezrin group was lower than that in baicalein group and that of the dual inhibitory group was the lowest. ( ${ }^{*} \mathrm{P}<0.05$ vs $\mathrm{NC}$ Control; ${ }^{* *} \mathrm{P}<0.01$ vs NC Control; \#P<0.05 vs baicalein group; $\&$ P $<0.05$ vs si-Ezrin group). 


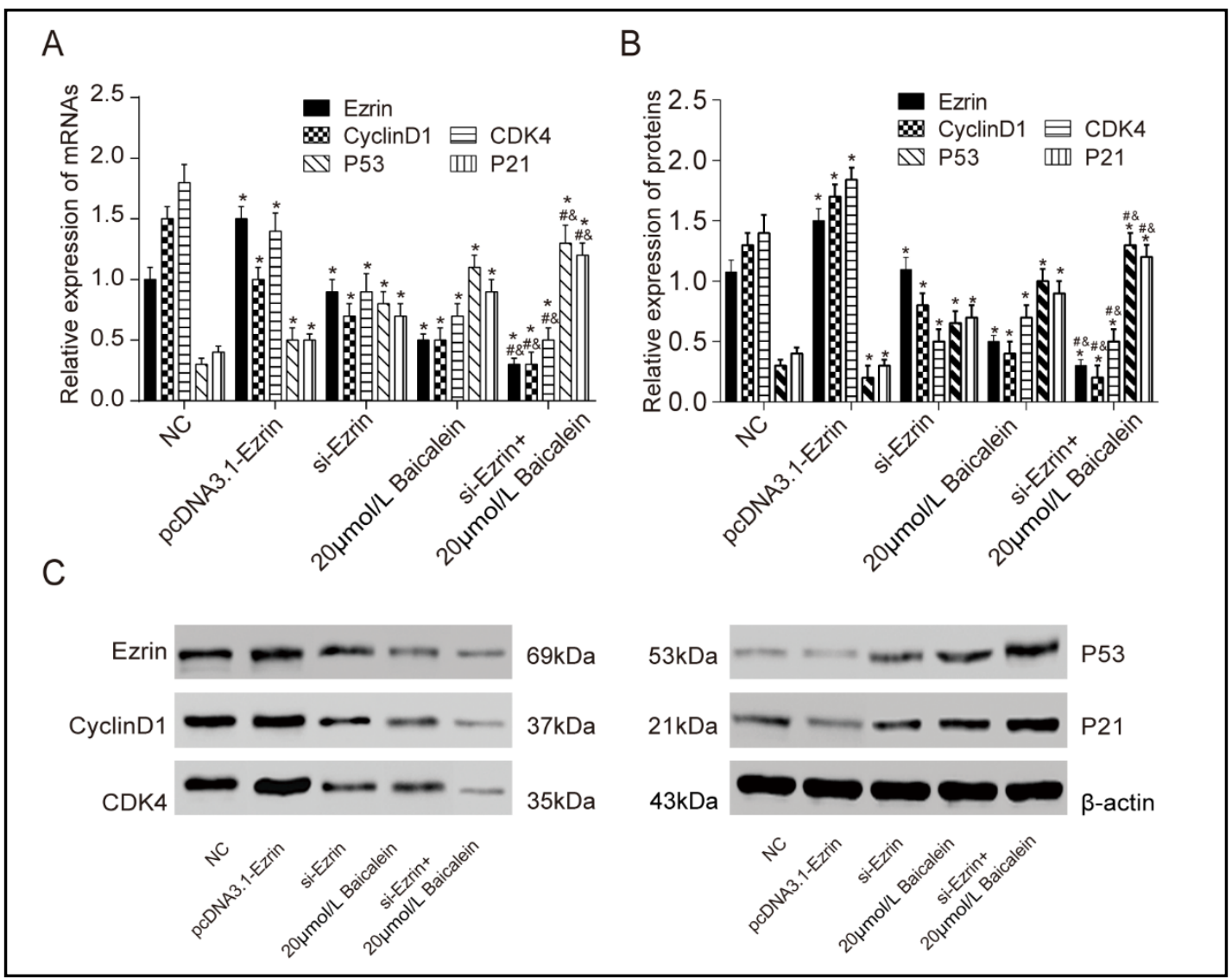

Fig. 5. Mechanisms about effects of si-Ezrin on cell cycle arrest of HCT116 cells. (A) The mRNA expression levels of Ezrin, as well as cell-cycle regulatory proteins CyclinD1 and CDK4 and P53 pathway-related proteins P53 and P21, were detected by qRT-PCR. (B-C) The protein expression levels of the factors mentioned above were validated by Western blot. $\left({ }^{*} \mathrm{P}<0.05\right.$ vs NC Control; ${ }^{* *} \mathrm{P}<0.01$ vs NC Control; $\# \mathrm{P}<0.05$ vs baicalein group; \&P<0.05 vs si-Ezrin group).

that both si-Ezrin and baicalein significantly inhibited the proliferation ability of HCT116 cells, indicating that baicalein might indeed inhibit HCT116 cell propagation through downregulating Ezrin.

Mechanisms about effects of si-Ezrin on cell cycle arrest of HCT116 cells

The mRNA or protein expression levels of Ezrin, as well as cell-cycle regulatory proteins CyclinD1 and CDK4 and P53 pathway-related proteins P53 and P21, were determined by using qRT-PCR (Fig. 5A) and Western blot (Fig. 5B-5C). Ezrin was distinctly upregulated with transfection of pcDNA3.1-Ezrin but observably downregulated with transfection of si-Ezrin. The expression levels of Ezrin in dual inhibitory group indicated inhibition to the greatest degree $(P<0.05)$. The expression of CyclinD1 and CDK4 was gradually decreased while the expression levels of P53 and P21 were observably increased in si-Ezrin group, $20 \mu \mathrm{mol} / \mathrm{L}$ baicalein group and dual inhibitory group compared with NC group, among which the changes in dual inhibitory group were most obvious. The results suggested that the pharmacological effects of baicalein on cell cycle inhibition were likely to be related to the cross-talk of Ezrin and P53 pathway.

Synergistic actions of Ezrin and baicalein on colorectal carcinoma in vivo

HCT116 cells transfected were subcutaneously inoculated into nude mice, which were divided into NC group, $50 \mathrm{mg} / \mathrm{kg}$ baicalein group, Ezrin-shRNA group and Ezrin-shRNA+50 $\mathrm{mg} / \mathrm{kg}$ baicalein group (Fig. 6A). Both baicalein and Ezrin-shRNA had inhibitory effects on the tumor growth, and the dual inhibitory (Ezrin-shRNA $+50 \mathrm{mg} / \mathrm{kg}$ baicalein) group reduced 


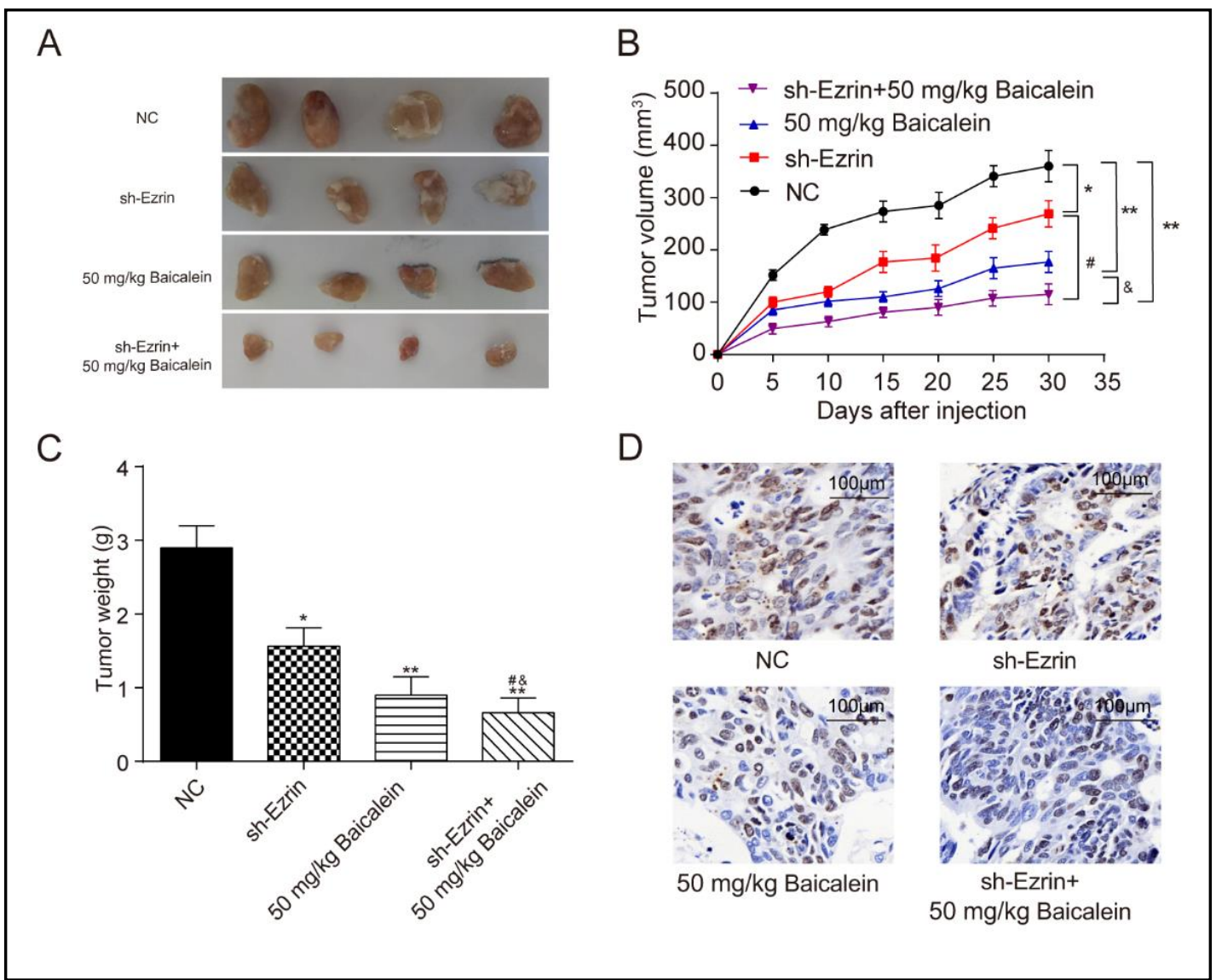

Fig. 6. Synergistic actions of Ezrin and baicalein on colorectal carcinoma in vivo. (A) Nude mice were inoculated subcutaneously with HCT116 cells. At the end of the treatment period, mice were sacrificed and tumor specimens harvested. (B) The tumor volume (V) was determined. (C) The tumor weight was measured. (D) Tumor specimens were subjected to immunohistochemical staining for Ki67 expression. $\left({ }^{*} \mathrm{P}<0.05\right.$ vs NC Control; ${ }^{* *} \mathrm{P}<0.01$ vs NC Control; $\# \mathrm{P}<0.05$ vs sh-Ezrin group; $\& \mathrm{P}<0.05$ vs baicalein group).

the volume of tumor for a complete synergy of action. It was noteworthy that tumor volume in the dual inhibitory (Ezrin-shRNA+50 $\mathrm{mg} / \mathrm{kg}$ baicalein) group was minimized among the experimental groups $(P<0.01$, Fig. 6B). Meanwhile, the weights of tumors presented the same tendency (all $P<0.05$, Fig. $6 \mathrm{C}$ ). To further understand the potential roles of Ezrin and baicalein on the molecular basis, we performed immunohistochemical staining and detected the expression levels of cell proliferation-associated Ki67 protein. The double-suppression of $50 \mathrm{mg} / \mathrm{kg}$ baicalein and Ezrin-shRNA could markedly reduce Ki67 expression (Fig. 6D).

\section{Discussion}

Colorectal cancer (CRC), also known as bowel cancer and colon cancer, is a major health issue among people worldwide. Upon the initial presentation, approximately $26 \%$ of CRC patients will be attacked by stage II disease while another $30 \%$ will develop stage III disease [20]. Despite that more intensive researches are ongoing, validated predictive markers and effective adjuvant therapies beneficial for stage II or III CRC are lacking [21]. While surgery alone may be curative in $70 \%$ of patients with localized (stage II \& III) CRC, a proportion of those eventually suffers from tumor recurrence and ultimately dies of metastatic disease [22]. In addition, the benefits of adjuvant therapies remain controversial. Therefore, more advances in understanding the drivers underlying biologic hallmarks of CRC are urgently expected to translate into practical application for making therapeutic strategy, getting rid of 


\section{Cellular Physiology Cell Physiol Biochem 2018;49:2035-2046

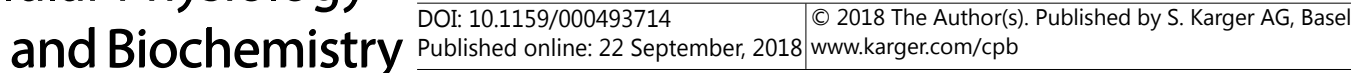 \\ Chen et al.: Baicalein Affects HCT116 Cells by Regulating Ezrin}

its shortcoming and taking its advantage. In the study, we studied the effects of baicalein and Ezrin on CRC in vitro and further testified our assumption in vivo with the nude mice model.

Baicalein is an active metabolite of enteral microbiome extracted from baicalin, which is a major ingredient of Scutellaria baicalensis as an herbal medicine commonly used in many Asian countries [12]. Combination of baicalein and other natural products can effectively modulate colorectal tumorigenesis. For instance, baicalein and betaine might be applicable to the prevention of colitis-associated colon cancer [23]. Other compounds derived from the Chinese herb, such as wogonin [24], luteolin [25] and negletein [26], can have a synergistic effect on prevention and suppression of CRC as well. Signaling pathways are involved in its function of anti-CRC, including activation of the Nrf2 signaling pathway [27] and attenuation of the MAPKs and PI3K-Akt activation [28]. As for other common malignant tumors, several reports have revealed various kinds of signal paths mediated by baicalein $[8,29,30]$. In the most important part of our research, we examined the proliferation of HCT116 cell periods by CCK-8 assay and flow cytometry (FCM). Our research investigated that baicalein could inhibit proliferation activity of HCT116 cells via down-regulating Ezrin and increasing P53 pathway-related protein expression.

Ezrin is a protein family member as well as a conduit for signals between metastasisassociated cell-surface molecules and signal transduction components [31]. Ezrin gene expression and protein production have been reported to be aberrantly regulated in many kinds of human cancers. Ben-Shmuel A et al. conducted a transcriptomics analysis and found that IGFBP-2 was a target of Ezrin and promoted CRC progression via NF- $\kappa B$ signaling [32]. Here, we identified the expression levels of Ezrin among CRC tissues of different pathologic grades and observed higher expression levels in poorly-differentiated CRC tissues compared with in well- and moderately-differentiated CRC tissues. In addition, we investigated the proliferation activity of HCT116 cells with the combined treatment of baicalein and siEzrin. As a result, there was a natural synergy between baicalein and si-Ezrin to enhance antitumorgenesis of CRC.

Nevertheless, a more in-depth research should be carried out to figure out the specific role of P53 pathway in CRC and the underlying mechanism between baicalein and P53 pathway. For further study, we could take the NF- $\mathrm{BB}$ signaling into account since this signaling pathway was associated with both Ezrin and baicalein.

\section{Conclusion}

In conclusion, our research demonstrated that baicalein acted as a key regulator in human colorectal carcinogenesis and revealed the regulatory network of baicalein and Ezrin. These results provided a deeper insight into CRC pathogenesis. Moreover, the pleiotropic effects of baicalein on colorectal cancer tumorigenesis suggested that it could be an effective target for antineoplastic therapies.

\section{Acknowledgements}

This work was partly supported by Industry Technology Research and Development Project of Jilin Province of China (2013C014-2); Scientific and Technological Development Project of Jilin Province of China (20140204028YY); Industry Technology Research and Development Project of Jilin Province of China (2014Y083). All experiments involved humans were administered properly under the medical ethics committee of First Hospital of Jilin University and we came to an agreement in advance with patients involved. All procedures involved animals were performed aseptically in accordance with the institutional guidelines of First Hospital of Jilin University and approved by the Experimental Animal Ethics Committee of First Hospital of Jilin University.

\section{Disclosure Statement}

The authors declare no potential conflict of interests. 


\section{Cellular Physiology Cell Physiol Biochem 2018;49:2035-2046 and Biochemistry Published \begin{tabular}{l|l} 
DOI: 10.1159/000493714 2018 The Author(s). Published by S. Karger AG, Basel \\
www.karger.com/cpb
\end{tabular} \\ Published onlıne: 22 September, 2018 whw}

\section{References}

1 Tamas K, Walenkamp AM, de Vries EG, van Vugt MA, Beets-Tan RG, van Etten B, de Groot DJ, Hospers GA: Rectal and colon cancer: Not just a different anatomic site. Cancer Treat Rev 2015;41:671-679.

2 Birt DF, Phillips GJ: Diet, genes, and microbes: complexities of colon cancer prevention. Toxicol Pathol 2014;42:182-188.

-3 Vogelstein B, Papadopoulos N, Velculescu VE, Zhou S, Diaz LA, Jr., Kinzler KW: Cancer genome landscapes. Science 2013;339:1546-1558.

4 Fearon ER: Molecular genetics of colorectal cancer. Annu Rev Pathol 2011;6:479-507.

5 Verhaar S, Vissers PA, Maas H, van de Poll-Franse LV, van Erning FN, Mols F: Treatment-related differences in health related quality of life and disease specific symptoms among colon cancer survivors: results from the population-based PROFILES registry. Eur J Cancer 2015;51:1263-1273.

6 Li SF, Tang JJ, Chen J, Zhang P, Wang T, Chen TY, Yan B, Huang B, Wang L, Huang MJ, Zhang ZM, Jin DD: Regulation of bone formation by baicalein via the mTORC1 pathway. Drug Des Devel Ther 2015;9:51695183.

7 Liu A, Wang W, Fang H, Yang Y, Jiang X, Liu S, Hu J, Hu Q Dahmen U, Dirsch O: Baicalein protects against polymicrobial sepsis-induced liver injury via inhibition of inflammation and apoptosis in mice. Eur J Pharmacol 2015;748:45-53.

-8 Guo Z, Hu X, Xing Z, Xing R, Lv R, Cheng X, Su J, Zhou Z, Xu Z, Nilsson S, Liu Z: Baicalein inhibits prostate cancer cell growth and metastasis via the caveolin-1/AKT/mTOR pathway. Mol Cell Biochem 2015;406:111-119.

-9 Bie B, Sun J, Li J, Guo Y, Jiang W, Huang C, Yang J, Li Z: Baicalein, a Natural Anti-Cancer Compound, Alters MicroRNA Expression Profiles in Bel-7402 Human Hepatocellular Carcinoma Cells. Cell Physiol Biochem 2017;41:1519-1531.

10 Han Z, Zhu S, Han X, Wang Z, Wu S, Zheng R: Baicalein inhibits hepatocellular carcinoma cells through suppressing the expression of CD24. Int Immunopharmacol 2015;29:416-422.

11 Aryal P, Kim K, Park PH, Ham S, Cho J, Song K: Baicalein induces autophagic cell death through AMPK/ ULK1 activation and downregulation of mTORC1 complex components in human cancer cells. FEBS J 2014;281:4644-4658.

-12 Wang CZ, Zhang CF, Chen L, Anderson S, Lu F, Yuan CS: Colon cancer chemopreventive effects of baicalein, an active enteric microbiome metabolite from baicalin. Int J Oncol 2015;47:1749-1758.

13 Ren L, Khanna C: Role of ezrin in osteosarcoma metastasis. Adv Exp Med Biol 2014;804:181-201.

14 Piao J, Liu S, Xu Y, Wang C, Lin Z, Qin Y, Liu S: Ezrin protein overexpression predicts the poor prognosis of pancreatic ductal adenocarcinomas. Exp Mol Pathol 2015;98:1-6.

15 Yu Z, Sun M, Jin F, Xiao Q, He M, Wu H, Ren J, Zhao L, Zhao H, Yao W, Shan F, Cao Y, Wei M: Combined expression of ezrin and E-cadherin is associated with lymph node metastasis and poor prognosis in breast cancer. Oncol Rep 2015;34:165-174.

16 Safi AF, Nickenig HJ, Rothamel D, Zirk M, Thiele 0, Grandoch A, Scheer M, Zinser M, Zoller J, Drebber U, Kreppel M: Expression of ezrin in oral squamous cell carcinoma: Prognostic impact and clinicopathological correlations. J Craniomaxillofac Surg 2015;43:1899-1905.

17 Kong J, Di C, Piao J, Sun J, Han L, Chen L, Yan G, Lin Z: Ezrin contributes to cervical cancer progression through induction of epithelial-mesenchymal transition. Oncotarget 2016;7:19631-19642.

-18 Yao Q, Zhao HY, Xie BZ: Effects of Ezrin and Heat Shock Protein 70 on Apoptosis and Proliferation of Human Osteosarcoma Cells. Orthop Surg 2015;7:273-280.

19 Leiphrakpam PD, Rajput A, Mathiesen M, Agarwal E, Lazenby AJ, Are C, Brattain MG, Chowdhury S: Ezrin expression and cell survival regulation in colorectal cancer. Cell Signal 2014;26:868-879.

-20 Goel G: Evolving role of gene expression signatures as biomarkers in early-stage colon cancer. J Gastrointest Cancer 2014;45:399-404.

21 Dienstmann R, Salazar R, Tabernero J: Personalizing colon cancer adjuvant therapy: selecting optimal treatments for individual patients. J Clin Oncol 2015;33:1787-1796.

-22 You YN, Rustin RB, Sullivan JD: Oncotype DX((R)) colon cancer assay for prediction of recurrence risk in patients with stage II and III colon cancer: A review of the evidence. Surg Oncol 2015;24:61-66.

23 Kim DH, Sung B, Chung HY, Kim ND: Modulation of Colitis-associated Colon Tumorigenesis by Baicalein and Betaine. J Cancer Prev 2014;19:153-160.

$>24$ Kim SJ, Kim HJ, Kim HR, Lee SH, Cho SD, Choi CS, Nam JS, Jung JY: Antitumor actions of baicalein and wogonin in HT-29 human colorectal cancer cells. Mol Med Rep 2012;6:1443-1449. 


\section{Cellular Physiology Cell Physiol Biochem 2018;49:2035-2046

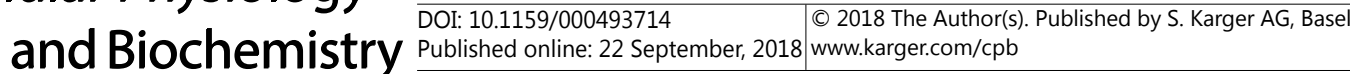

25 Palko-Labuz A, Sroda-Pomianek K, Uryga A, Kostrzewa-Suslow E, Michalak K: Anticancer activity of baicalein and luteolin studied in colorectal adenocarcinoma LoVo cells and in drug-resistant LoVo/Dx cells. Biomed Pharmacother 2017;88:232-241.

-26 Havermann S, Chovolou Y, Humpf HU, Watjen W: Modulation of the Nrf2 signalling pathway in Hct116 colon carcinoma cells by baicalein and its methylated derivative negletein. Pharm Biol 2016;54:1491-1502.

27 Havermann S, Rohrig R, Chovolou Y, Humpf HU, Watjen W: Molecular effects of baicalein in Hct116 cells and Caenorhabditis elegans : activation of the Nrf2 signaling pathway and prolongation of lifespan. J Agric Food Chem 2013;61:2158-2164.

-28 Kim SD, Lee YJ, Baik JS, Han JY, Lee CG, Heo K, Park YS, Kim JS, Ji HD, Park SI, Rhee MH, Yang K: Baicalein inhibits agonist- and tumor cell-induced platelet aggregation while suppressing pulmonary tumor metastasis via cAMP-mediated VASP phosphorylation along with impaired MAPKs and PI3K-Akt activation. Biochem Pharmacol 2014;92:251-265.

29 Shang D, Li Z, Zhu Z, Chen H, Zhao L, Wang X, Chen Y: Baicalein suppresses 17-beta-estradiol-induced migration, adhesion and invasion of breast cancer cells via the $\mathrm{G}$ protein-coupled receptor 30 signaling pathway. Oncol Rep 2015;33:2077-2085.

-30 Yan X, Rui X, Zhang K: Baicalein inhibits the invasion of gastric cancer cells by suppressing the activity of the p38 signaling pathway. Oncol Rep 2015;33:737-743.

-31 Wu G, Sun X, Yuan H, Hu M: Ezrin gene expression and protein production in the CD44(+) subpopulation of SCC-9 cells in a malignant oral cancer cell line in vitro. J Oral Maxillofac Surg 2013;71:e151-157.

-32 Ben-Shmuel A, Shvab A, Gavert N, Brabletz T, Ben-Ze'ev A: Global analysis of L1-transcriptomes identified IGFBP-2 as a target of ezrin and NF-kappaB signaling that promotes colon cancer progression. Oncogene 2013;32:3220-3230. 